\title{
Елена Стоянова
}

Шуменский университет им. Епископа Константина Преславского (Болгария)

\section{ЭМОТИВНАЯ СОСТАВЛЯЮЩАЯ СОВРЕМЕННОЙ ВКУСОВОЙ МЕТАФОРЫ (НА МАТЕРИАЛЕ РУССКИХ И БОЛГАРСКИХ МЕДИАТЕКСТОВ)}

В рамках современной антропоцентрической парадигмы научных исследований усиливается интерес к изучению метафоры как средства описания внутреннего мира человека, его интеллектуальной деятельности, чувств и эмоций. Как известно, эмоции представляют собой психические реакции человека на различные раздражители извне и воспринимаются одним из главных механизмов регуляции его познавательной деятельности (БПС 2003), а их отображение в языке репрезентирует эмотивность.

Сложность языкового кодирования эмоций и большой накопленный учеными эмпирический материал обусловливает обособление в конце XX века эмотиологии или лингвистики эмоций в отдельную научную отрасль. Ее усилия направлены на исследование субъективных компонентов в значении языковых единиц, на формирование и структурирование знаний об эмотивном коде языка (см.: Шаховский 1996).

В силу многоаспектности категории эмотивности, наряду с традиционными лингвистическим, стилистическим, философским и психологическим подходами, в современной науке утверждается полипарадигмальное осмысление данного феномена. Эмотивность рассматривается с позиций психолингвистики (Н. В. Витт, В. Н. Гридин, А. М. Шахнарович и др.), лингвокультурологии (А. Вежбицкая, С. Г. Воркачев, В. Н. Телия, И. В. Томашева и др.), когнитивной лингвистики (А. Г. Баранов, Е. Книпкенс, Ч. Филлмор, Р. Цваан) и т.п. В лингвокогнитивном аспекте эмотивность рассматривается в качестве когнитивной структуры в сознании человека, которая связывается с конкретной ситуацией эмоционального оценивания (см.: подр. Телия 1986; Филлмор 1983, 1988; Человеческий... 1991: 114 и др.).

Формирование языка эмоций относится к древнейшему периоду концептуализации мира и происходит в соответствии с мифологическими представлениями. Исследователями (А. Вежбицкая, Н. Д. Арутюнова, Ю. Д. Апресян, В. Ю. Апресян и др.) демонстрируется, что эмоции, являю- 
щиеся в современном понимании некими лингвокогнитивными абстракциями, отождествляются в древности с объектами предметного мира (огонь, влага, ветер, живое существо и т.д.) и носят архетипический характер.

Важным орудием в процессе формирования эмотивности является метафора. Базируясь на аналогии с наблюдаемыми свойствами и признаками предметов, признаковая метафора формирует область вторичных предикатов - прилагательных и глаголов, выступающих характеризацией непредметных сущностей. В их основе в русском языке лежит, преимущественно, сенсорно-перцептивный признак (зрительный, слуховой, вкусовой, обонятельный, осязательный или тактильный). Ощущаемые с помощью органов чувств характеристики переносятся на объекты и явления без четкого соотнесения с определенным классом субъектов. Например: сладкая жизнь, сладкая женщина, сладкий сон, сладкая радость, сладкие мечты, сладкие воспоминания, сладкий голос, сладкие речи, сладкая ульгка; горькая печаль, нежное чувство, страшный гнев и т.п.

Эмотивная коннотация как чувственная (эмоциональная) и оценочная характеристика объекта, транслируемая метафорическим образом, представляется одним из важнейших путей имплицитного или эксплицитного воздействия на интеллект, волю и эмоциональное состояние адресата. В медиадискурсе эмотивность метафоры прогнозируется автором медиатекста, в соответствии с гипотезой о когнитивной матрице структурирования и хранения знаний о мире, лежащей в основе высказанной М. Минским теории фреймов (Минский 1979). Ее декодирование осуществляется адресатом, который не только восстанавливает «референцию сообщения, но и замысел, или цель, сообщения, в частности - интенцию говорящего, связанную с тем, чтобы вызвать эмотивную реакцию адресата» (Человеческий ... 1991: 18).

В базовую установку метафоры заложен рациональный фактор оценки (хорошо - плохо, положительный - отрицательный), который, как правило, прочитывается адресатом сразу, поскольку эти «посылы» базируются на традиционном знании как понятийной сферы метафоризации, часто обусловливаются выбором той или иной метафорической модели и степенью ее структурированности в сознании носителя лингвокультуры. Кроме того, рациональная оценка дополняется личностным эмоциональным восприятием метафоры ${ }^{1}$. Специфика эмотивной коннотации может проявляться и в зависимости от той или иной конкретной ситуации или метафорического контекста. Таким образом, метафора способна выступать средством формирования и передачи как ингерентной, так и адгерентной эмотивности.

${ }^{1}$ Иррациональная оценка, которая может быть установлена психолингвистическими методами, в данной работе не принимается во внимание. Кроме того, моделирование метафорической эмотивности регламентируется коммуникативной (и в частности, лингвокультурной) компетентностью говорящего и зависит от подобной компетентности декодирующего ее адресата, показатели которых не детализируются. 
В аспекте контрастивных исследований принимается во внимание еще один факт эмотивности метафоры. В качестве лингвокогнитивной формы структурирования, моделирования и хранения информации метафора несет в себе «универсальную» эмотивность. В условиях современной глобализации как всеобщей тенденции развития лингвокультур наблюдается определенная универсализация медиадискурса, что часто обусловливает зеркальность метафорических образов, функционирующих в различных языках. Однако при всем при этом они могут различаться в различных лингвокультурах эмотивной коннотацией. Следовательно, в метафоре находят отражение этнокультурная (ведущая в мифологию и культурную традицию) и социокультурная (соотносимая с той или иной лингвокультурной ситуацией) составляющие 2 . Таким образом, при учете одного из основных ориентиров когнитивного механизма - культурного компонента (Стоянова 2012а: 80-86), который неизменно включается в процесс метафоризации, эмотивность приобретает национальный характер.

Целью данной статьи и является обращение к эмотивной коннотации русской и болгарской вкусовой метафоры. Как известно, сфера источника вкусовой метафоры отличается относительным постоянством во времени, что в значительной степени выделяет эту метафору среди других, поскольку вкусовые ощущения человека характеризуются определенной стабильностью и относительной неизменностью. На наш взгляд, сравнительное исследование подобной консервативной сферы в свете соотношения национального и общечеловеческого видения мира на материале различных языков представляет несомненный научный интерес. Материалом исследования выступают русские и болгарские медиатексты разных жанров выборочной подборки периода последнего десятилетия. Для сопоставительного анализа выбраны национальные печатные издания и электронные ресурсы (росс. Комсомольская правда, Труд, Независимая газета, Московский комсомолец, Новая газета и др.; болг. Дума, 24 часа, Сега, Стандарт, Новинар, Монитор и др.).

Как известно, информацию о мире человек с древности получает посредством вкусовых ощущений как процесса практического познания истины. Мифические представления о познании соотносятся со вкушением плода (ср.: Вкусить от древа познания). Искушение вкусом Адама и Евы привели к познанию тайны продолжения жизни. Философское осмысление мира посредством вкуса (ср.: лат. De gustibus non est disputandum, русск. О вкусах не спорят; болг. За вкусовете не трябва да се спори) и народная мудрость (русск. На вкус и ивет товарищей нет; У кого какой вкус: кто любит дыню, а кто арбуз; У всякого свой вкус, один другому не указчик: кто любит арбуз, в кто свиной хрящик; болг. (На) вкус другар няма) свидетель-

${ }^{2}$ Используемый в статье термин культурный включает как этнокультурную, так и социокультурную составляющую. 
ствуют о различии людей и народов, следующих по своему собственному пути познания. Несмотря на универсальность физиологического строения человека, у разных народов устанавливается свой собственный вкусовой стандарт, и наблюдаются различия в восприятии окружающей действительности посредством вкусовых ощущений.

В современном российском и болгарском медиадискурсах вкусовая метафора является активным стилистическим ресурсом для привлечения внимания, представления и оценки той или иной ситуации, обеспечивая требуемое в этих целях упрощение, конкретизацию или, наоборот, размывание понятий. Анализ собранного метафорического материала в рамках современной лингвокультурной ситуации позволяет схематично представить структуру метафорической модели 'Общество вкусовые ощущения' в виде двух основных фреймов: 'Основные вкусы и их оттенки' и 'Оценка вкусовых ощущений', состоящие из соответствующих слотов, в которых разграничиваются различные концептуальные векторы и сценарии. Материал, относящийся к первому фрейму, уже подвергался частичному анализу (Стоянова 2012б: 255-258; Стоянова 2014: 46-78). На этом основании внимание данной статьи направлено на второй фрейм, представляющий эмотивный компонент вкусовой метафоры. В указанном фрейме разграничиваются два основных слота: 'Мелиоративная / дерогативная оценка' и 'Дополнительная оценка'.

\section{СЛОТ 1. 'МЕЛИОРАТИВНАЯ / ДЕРОГАТИВНАЯ ОЦЕНКА'}

В связи с аксиологической интерпретацией фиксируется параметризация эмотивной коннотации вкусовой метафоры, что подразумевает членение оценки на положительную / отрицательную. Именно данная характеристика лежит на поверхности эмотивного восприятия данной метафоры и соз-

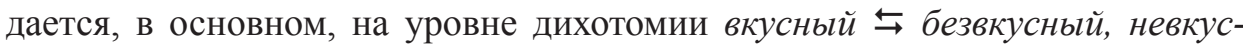
ный. Например: русск. В идеале «Магнитка» приучила любящего ее зрителя к хоккею вкусных комбинаций, игровому, на исполнение - как и «Барселона» (Советский спорт 11.12.2008); Табаков играет его сочно, «вкусно», в такого мужчину хочется влюбиться, несмотря на возраст (Труд-7 29.05.2004); Рулю не хватает остроты реакиии, из-за чего управляемость какая-то «невкусная》, нет в ней азарта, зато есть уверенность (Комсомольская правда 16.11.2007); К сожалению, хорошая идея акцентировать внимание на межнацииональной толерантности и этнокультурном многообразии Украины получила безвкусное исполнение и превратилась в бессмысленную пародию (Комсомольская правда 15.08.2010) и болг. Вкусен спектакъл от 
Ирландия кани на вечеря за двама в Младежкия (Новинар 27.10.2007); Днес всеки може да направи партия, да участва в изборите, всеки може да говори по медиите, лидерите на протестиращите не слизат от екраните, и това е неоспорим факт, който се вижда с просто око, достатъчно е да си пуснеш телевизора. Паралельт между тоталитарния режим и посттоталитарния, в който живеем, е плосък, безвкусен и неприличен (Репортер 03.11.2013).

Специфику вкусовой метафоры составляет наличие рациональной оценки и эталонности (хорошо - плохо) соотносимого объекта или явления. Чаще всего данная оценка традиционно закрепляется в лингвокультуре и сопровождает тот или иной формирующийся образ на основе общепринятого вкусового восприятия. В процессе развития человечества естественная чувствительность преображалась, постепенно ломались стереотипы. На традиционном восприятии определенных продуктов и вкусовых ощущениях, связанных с ними, базируется имплицитная оценка, например, указанной ниже современной вкусовой метафоры. Например: русск. В две медовые ничьи, которые белорусская сборная привезла из Германии и Финляндии, попала ложка дегтя (Комсомольская правда 06.06.2008); Судя по всему, у Билялетдинова есть самолюбие, он вступает в самый сочный футбольный возраст - у него есть все шансы заиграть в Англии, чего ему и желаю (Советский спорт 26.08.2009) и болг. А за сърбите в Косово какво остава? Единствено да преглътнат веднъж завинаги горчивия хап, че живеят извън собствената си държава и полека-лека да започнат да се интегрират (Дума 19.09.2011); Сан Антонио е новият шампион на НБА. «Шпорите» детронирах Маями с 4:1 победи във финалната серия. Трофеят е пети във витрината на «ипорите», като те взеха сладък ревани от Хийт, след като именно Маями е единственият отбор, нанасял им поражение във финали - през миналия сезон (iNews.bg 16.06.2014).

Традиционно сладкий и соленый в русской лингвокультуре воспринимались с положительным знаком и соответствовали понятию вкусный в отличие от безвкусной и пресной пищи. Ср.: русск. Отнюдь, Кольциов «вкусным» кистевым броском от синей линии вновь устанавливает равенство (Советский спорт 23.12.2006); Будем надеяться, что уж в этом поединке старина Тайсон не промахнется и пошлет своего соперника в сладкий нокаут (Комсомольская правда 05.08.2005) - На перерыв «Локомотив» уходит, имея в активе разве что пресный удар головой Одемвингие (Советский спорт 15.06.2009).

Наоборот, горький вкус исторически ассоциировался с неприятным ощущением. Подобное негативное отношение к горькому вкусу, складывавшееся в древности интуитивно (ср.: русск. Хуже горькой редьки), совпадает с заключением эволюционной биологии о токсичности горьких растений. Однако в болгарской лингвокультуре допускается двойственность и про- 
тиворечивость восприятия указанной метафоры. Ср.: Истинското вино е горчиво (букв. настоящее вино имеет горький вкус), где горькая метафора воспринимается положительно, и пейоративно звучащие метафоры: ГЕРБ получи горчив «подарък» за седмия си рожден ден. Търновският депутат Георги Марков изненадващо подаде заявление за напускане на парламентарната група на бившите управляващи (Стандарт 03.12.2013); Горчив хап за ияла Европа. Лидерите на Европейския съюз сринаха банковата система на Кипър за назидание на другите си дльжници (Дума 25.04.2013).

Кисльй (в силу незрелости плода) также традиционно воспринимался со знаком минус. Однако с течением времени происходит изменение вкуса - теперь не возможно дать однозначной оценки таким вкусовым ощущениям, как: соленый, кислылй, жирный. (Ср.: например, болг. кисело зеле, кисело мляко (квашеная капуста, йогурт), русск. кисло-молочные продукты, то есть приготовленные путем квашения, брожения, и кислый суп - вкиснала супа, то есть испорченный, прокисший). Острый же вкус продукта, толкуемый часто отрицательно, нередко придает особую пикантность и изысканность пище.

С положительной коннотацией актуальности и важности звучат следующие русские вкусовые метафоры соленая правда, острая проблема. Например: В. Путин: С пивом хорошо соленую правду (Голос России 15.12.2012); A депутат Олег Куликов, член ЦК КПРФ, добавил: "Сами понимаете, что за минуту охватить все острые проблемы невозможно» (Независимая газета 07.04.2011).

В болгарской метафоре жгучий вкус ассоциируется с ярым пристрастием, почитанием чего-либо: Сетих се обаче, че от няколко години у нас БСП въведе «диш хакъ». Едно време българите - блюстители на чистотата на езика на Кирил и Методий (на което съм лют привърженик), са му викали «данък десятък». Сега модерните либерални икономисти го възхваляват като «плосък данък»... (24 часа 06.01.2014).

Рациональностью характеризуются одобрительная / неодобрительная эмоциональная оценка. С неодобрением, например, воспринимаются некоторые «кислые» метафоры русского и болгарского медиадискурсов: русск. Медведев поручил открыть аэропорт «Бельбек» для гражданской авиации. «Единственное - его, конечно, нужно привести в порядок, потому что, как многие другие объекты, на территории Республики Крым и Севастополя, он находится в довольно таком кислом состоянии (РИА Новости 16.06.2013); ...nрестиж рабочей профессии в нашей стране крайне низок, и “кислый” образ российского рабочего необходимо менять (РБК Daily 31.08.2010); Разговорами о том, что старые драйверы роста уже не могут, а новых ещуе нет, правительство и экономисть давно набили друг другу оскомину, видимо, полагая, что правильно поставленный диагноз - это уже полдела (Интерфакс 30.12.2013) и болг. ДС и БКП - брак с кисела физиономия (Дневник 20.04.2008). 
Нередко кислый вкус соотносится с незначительностью, что может толковаться со знаком плюс. Например: русск. Уровень коррупциии внизу кислый, а наверху - колоссальный. А благодаря вопросу предпринимателя из Нижнего Новгорода Олега Кондрашева, кандидат в президенты приоткрыл завесу над тем, как и когда в стране начнут бороться с коррупичией (Комсомольская правда 27.02.2008) и болг. Сигурен съм, че тези мои разсъждения щуе срещннат оня кисел сарказъм и самодоволството на реванша, с които са залети форумите и сочиалните мрежи. Ще се сбльскат и с объркването и обидата, обвзели хората, които се надяваха, че най-сетне с правителството на Орешарски щзе започне промяната и нормализацията на страната към по-добро, каквито бяха и обещуанията преди и след изборите (Дума 19.06.2013); Чиновникът - тази неизтребима класа. Четата му е всявала кисел ужас сред богатите, а пък бедните направо са го обожавали и често са го укривали от потери и войска, защуото се е правел на Робин Худ. Властта го е преследвала, но без да си дава много зор, обаче след като прави неуспешен опит да задигне пет милиона от държавната банка в Хасково, хайдутинът съвсем озверява (Дума 04.06.2011).

Неоднозначно воспринимается русская метафора кислая экономика. Например, Медведев: состояние экономики РФ «кислое», но лучше, чем в Евpone (РИА Новости 06.12.2013). С одной стороны, кислый вкус ассоциируется с начавшимся процессом брожения, активизации. Но с другой - если подобное состояние продолжается долго, то продукт теряет свою ценность и портится.

Ингерентная эмотивность в качестве положительной / отрицательной характеристики создается на уровне дихотомии вкусный, аппетитный, лакомылй $\leftrightarrows$ безвкусный, невкусный, пресныли; а положительная вкусовая реакция на сладкое противопоставляется в некоторых ситуациях двум вкусам - горь-

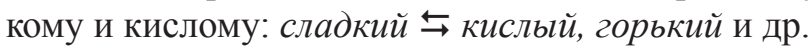

В медиатекстах наблюдается наличие адгерентной эмотивности, размывающей категоричность противопоставления. Метафоры (вкусный, anпетитныц̆, лакомый) уже не воспринимается основным адресатом с положительной оценкой, а вызывают негативные ассоциации и квалифицируют средство наживы горстки людей. Например: русск. «Самой вкусной» сделкой в рамках проведенной в текущем году приватизащии стала продажа акиий алмазодобывающей компании «Алроса» (Lenta.ru 11.12.2013); Но часть из построенного жилья отдайте городу - в среднем получается треть, хотя в ияентре и других «вкусных» районах забираем больше, а в тех, что не пользуются спросом, вообще иной раз не требуем доли - лишь бы жилой фонд прирастал (Труд-7 22.02.2001); Очевидно, что самые лакомые кусочки государственной собственности уже давно проданы, и последние три года план приватизации выполняется лишь на 50-60\% (РБК Daily 18.08.2008) и болг. Бойко Борисов: Точната формулировка, ко- 
ято трябва да се използва, е, че всичко, което е можело да носи приходи, отдавна вече е приватизирано. Вкарваме го в забранителния списък-оттук нататък, това, което опосканото е останало, да не бъде приватизирано. Не че някой ще иска да го купи, а просто да спрем популистите с льжите - тези, които са налапали вкусните хапки, да ги наречем, от Софиянски (Репортер 27.05.2011).

Адгерентная эмотивность прослеживается в ряде случаев «сладкой» метафоры. Образы русск. медовый и болг. сладникъв (букв. сладковатый) в медиатекстах несут в себе сему слащавости, приторности, лицемерности. Например: русск. То ли в Кремле убедились, что медовые заверения Запада о равноправном партнерстве во многом лицемерны, то ли (и это скорее всего) наконеи увидели, что отступать нам дальше некуда - уперлись! (Комсомольская правда 13.02.2007) и болг. Това вече не е «гражданското общество», за което се сипеха сладникави суперлативи от страна на посланици, еврокомисар и президент. Защото на неговия фон призивите на Рединг и Плевнелиев звучат водевилно (Дума 25.07.2013).

\section{СЛОТ 2. 'ДОПОЛНИТЕЛЬНАЯ ОЦЕНКА'}

Эксплицитное формирование оценки чаще всего связано с использованием дополнительной идентификации. Указанный характер оценочной концептуализации фиксируется на лексическом уровне. Оценочная коннотация базируется на вкусовых результатах ряда оттенков и нюансов вкусов. Так, например, вкусовые оттенки приторный, слащавый придают отрицательный нюанс сладкому вкусу. Например: русск. Честно сказать, и мне тоже представлялось, что при нынешней обстановке поездка наших спортсменов в Грузию, покрываюшую чеченских бандитов, столь же унизительна, как, к примеру, фальшиво-приторное присутствие наших фигуристов при повторной выдаче золотых медалей на прошлой зимней Олимпиаде (Труд-7 17.10.2002); И я всерьез готовился к тому, что мои попытки разобраться в причинах «архангельского чуда» могут заблудиться во взаимных обвинениях, компроматах и приторных речах подчиненных «мудрых руководителей» (Комсомольская правда 28.08.2007).

В то время как эмотивная коннотация смачный (обычно соотносится с положительной семантикой вкуса) отличается неоднозначностью. Ср.: Еще чуть позже смачный удар шведов метров с 25 (Советский спорт 03.02.2005) - С другой стороны, успех «ППК» - это смачный плевок в лицо российского шоу-бизнеса, который, оказывается, совершенно не представляет, на кого надо делать ставку в деле завоевания западного рынка (Комсомольская правда 14.12.2001). 
Такие нюансы вкуса, как русск. сладковатый, горьковатый, кисловатый и болг. сладникъв, семантически соотносимые с частичностью, небольшим присутствием вкуса, метафорически транслирует незначительность вкусового эффекта. Например: русск. Я вполне доверяю Путину и в то же время не могу не замечать, что не только у меня, но и у многих остается какой-то горьковатый осадок от нашего сотрудничества (Труд-7 24.05.2002); С тех пор купание к Красном море не стало менее безопасным, зато отдых в роскошных отелях Шарм-эш-Шейха приобрел солоноватый привкус настоящзего драйва (Известия 29.12.2010); Несмотря на кисловатый прием спектакля искушенной публикой, Рудинштейн намерен выступить продюсером киноверсии «Губ», в которой, по некоторым сведениям, примут участие Алла Пугачева и Филипп Киркоров (Труд-7 14.06.2002) и болг. Огромна «заслуга» за тази масова снобария имат пак медитее, които ни «зарибяват» непрекъснато с образци на кичозните попарт и реклама-агресивни клипове, комикси и детски игри, заредени с престьпно насилие, сладникави сапунки и какво ли ощзе не (Дума 02.07.2011).

Дополнительный нюанс в метафорический образ привносят русск. привкус, болг. привкус, овкусен. Например: русск. «Пятое место в медальном зачете - настоящтая трагедия для России, а тот факт, что Россия будет принимать следуюшую зимнюю Олимпиаду, придает унизительный привкус», - пишет американский журнал Foreign Policy (Труд-7 05.03.2010); А уж если запах денег смешается с запахом власти, этот опасный симбиоз способен разрушить судьбы многих людей, оставляя после себя только привкус беды (Труд-7 30.04.2004) и болг. Състезание с криминален привкус се очертава и във варненската червена организация (Политика №82, 12-18.11.2005); Кристалина Георгиева: България е най-проевропейската страна. «Виждам много успели и уважавани българи, които допринасят за доброто име на страната ни». Един въпрос, който е много актуален за България - тютюнопушенето. Напоследък започнаха дебати около тази забрана, може би защуо тя има сладък предизборен привкус? (iNews.bg 01.01.2013); Извън каламбурите, наистина се опитвам да повярвам в добронамереността на Плевнелиев, въпреки че ми е все по-трудно. Всяка негова намеса в последните месеци води към единствена възможна последица в публичния живот - ощце по-голяма институциоонална криза, основана не само върху ниското доверие в парламентарно представените партии, но и допьлнително «овкусена» с институционална война между президент, Народно събрание и правителство (Репортер 08.08.2013) и др.

Итак, анализируемый материал медиадискурса демонстрирует моделируемую эмотивность современной вкусовой метафоры в ингерентной и адгерентной формах, что свидетельствует об имплицитно и экслицитно воздействующем эффекте данной метафоры в языке современных российских и болгарских СМИ. 


\section{Библиография}

Арутюнова Н. Д. (1999), Язык и мир человека, Москва.

Минский М. (1979), Фреймы для представления знаний, Москва.

БПС (2003), Большой психологический словарь, ред. Б. Г. Мещеряков и В. П. Зинченко, Москва, http://psychological.slovaronline.com/

Стоянова Е. (2012а), Метафора как соииокультурно обусловленный медиатекст, [в:] Медиатекст как полиинтенциональная система: сб. статей, ред. Л. Р. Дускаева, Н. С. Цветова, Санкт-Петербург, с. 80-86.

Стоянова Е. (2012б), К вопросу о функиионировании метафоры в русских и болгарских медиатекстах, [в:] Средства массовой информачии в современном мире: Петербургские чтения, Санкт-Петербург, с. 255-258.

Стоянова Е. (2014), Вкусовая метафора как средство конщептуализации современной действительности (на материале российского и болгарского медиадискурсов), «Годишник ШУ. Шумен», том XXVA, с. 46-78.

Телия В. Н. (1986), Коннотативные аспекты семантики номинативных единии, Москва.

Филлмор Ч. (1983), Основные проблемы лексической семантики, «Новое в зарубежной лингвистике», том XII, Москва.

Филлмор Ч. (1988), Фреймы и семантика понимания, «Новое в зарубежной лингвистике», том XXIII, Москва.

Человеческий фактор в языке: Языковые механизмы экспрессивности (1991), Институт языкознания; ред. В. Н. Телия, Москва.

Шаховский В. И. (1996), Эмоциональные культурные концепты: параллели и контрасты, [в:] Языковая личность: культурные конщепты, Волгоград, с. 80-96.

\section{Elena Stoyanova}

\section{THE EMOTIONAL CONNOTATION OF GUSTATORY METAPHOR IN RUSSIAN AND BULGARIAN MEDIA TEXTS}

(Summary)

The article examines the emotive connotation of gustatory metaphor in Russian and Bulgarian media texts. Area source of gustatory metaphors is relatively constant in time, because the taste sensation is characterized by a certain stability and relative permanence. Emotive connotation as an emotional and the evaluated characteristics of the object, transmitted by metaphorical way, seems to be one of the most important ways of implicit or explicit impact on the intellect, the will and the emotional state of the recipient. The main task of the article is to outline the second frame of submetaphor 'Evaluation of taste sensations', which consists of two main slots: 'positive / negative evaluation' and 'complementary evaluation'. The analyzed material shows the simulated emotive connotation of modern taste metaphors in inherent and adherent forms.

Keywords: language and culture, metaphor, media discourse, Russian and Bulgarian media texts. 


\section{Елена Стоянова \\ ЭМОТИВНАЯ СОСТАВЛЯЮЩАЯ СОВРЕМЕННОЙ ВКУСОВОЙ МЕТАФОРЫ (НА МАТЕРИАЛЕ РУССКИХ И БОЛГАРСКИХ МЕДИАТЕКСТОВ) \\ (Резюме)}

В статье рассматривается эмотивная коннотация вкусовой метафоры в русских и болгарских медиатекстах. Сфера источника вкусовой метафоры является относительно постоянной во времени, поскольку вкусовые ощущения характеризуется определенной стабильностью и относительным постоянством. Эмотивная коннотация как эмоциональная и оценочная характеристика объекта, транслируемая метафорическим образом, представляется одним из важнейших путей имплицитного или эксплицитного воздействия на интеллект, волю и эмоциональное состояние адресата. Основной задачей статьи является анализ второго фрейма метафорической модели «Оценка вкусовых ощущений», который состоит из двух основных слотов: «Позитивная / негативная оценка» и «Дополнительная оценка». Анализируемый материал медиадискурса демонстрирует моделируемую эмотивность современной вкусовой метафоры в ингерентной и адгерентной формах.

Ключевые слова: язык и культура, метафора, медиадискурс, российские и болгарские медиатексты. 